\title{
Time to Act
}

\author{
S.J. Connor, O. Abdulla, M.J. Naqvi, S. Shamshuddin
}

\section{CLINICAL PRESENTATION}

A 52 year old female presented with 2.5 hour history of dense right sided weakness with confusion. Past medical history of renal cell carcinoma and bilateral pulmonary metastases.

\section{IMAGES - UNENHANCED COMPUTED TOMOGRAPHY (CT) BRAIN}

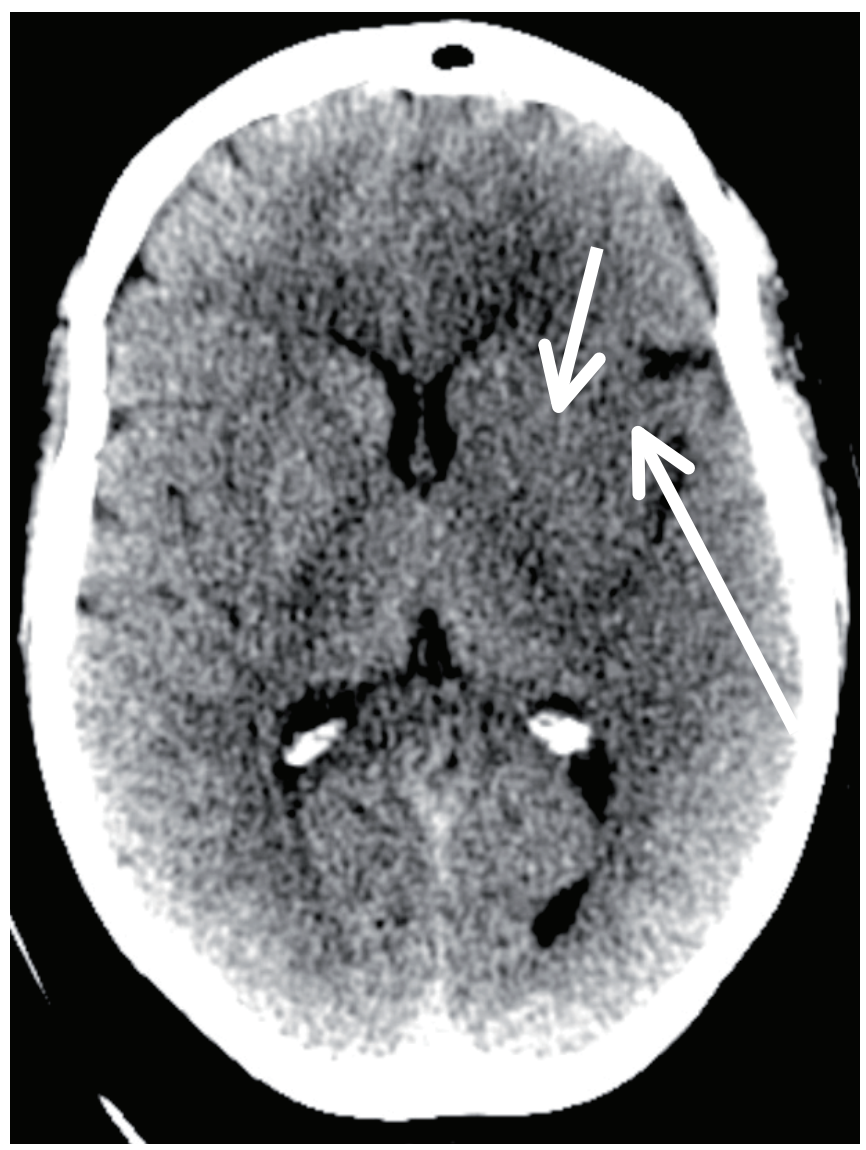

Figure 1a: 2.5 hours after onset - shows hypo-attenuation of the left lentiform nucleus (short arrow) and insular ribbon (long arrow)

\section{DIAGNOSIS}

Hyper-acute left anterior (ACA) and middle cerebral artery (MCA) infarct. No evidence of intracerebral haemorrhage.

\section{RADIOGRAPHIC FEATURES}

\section{Immediate}

Hyper-dense vessel representing visualisation of thrombus/ emboli e.g. hyper-dense MCA sign

\section{Hyper acute (0-6 hours)}

Loss of grey white matter differentiation and hypo

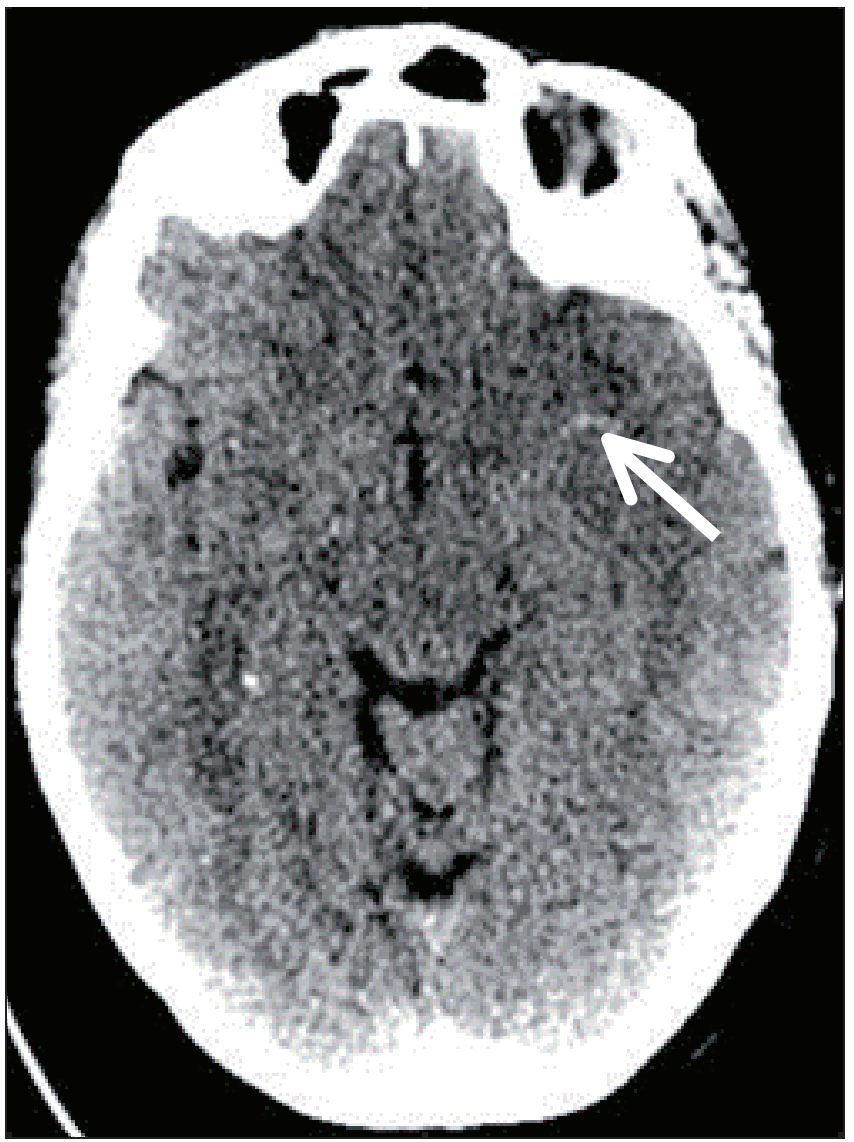

Figure 1b: 2.5 hours after onset - shows a left sided hyper-dense middle cerebral artery (MCA) sign (arrow)

attenuation of deep nuclei:

- Lentiform nucleus changes seen as early as 1 hour after occlusion and visible in $75 \%$ of patients at 3 hours.

Cortical hypo-density with parenchymal swelling and sulcal effacement:

- The first sign of this is usually 'loss of the insular ribbon', as it is more vulnerable due to poor collateral blood supply.

\section{Late hyper acute (6-24 hours)}

Swelling and hypo attenuation increases which displaces surrounding tissue (mass effect). 


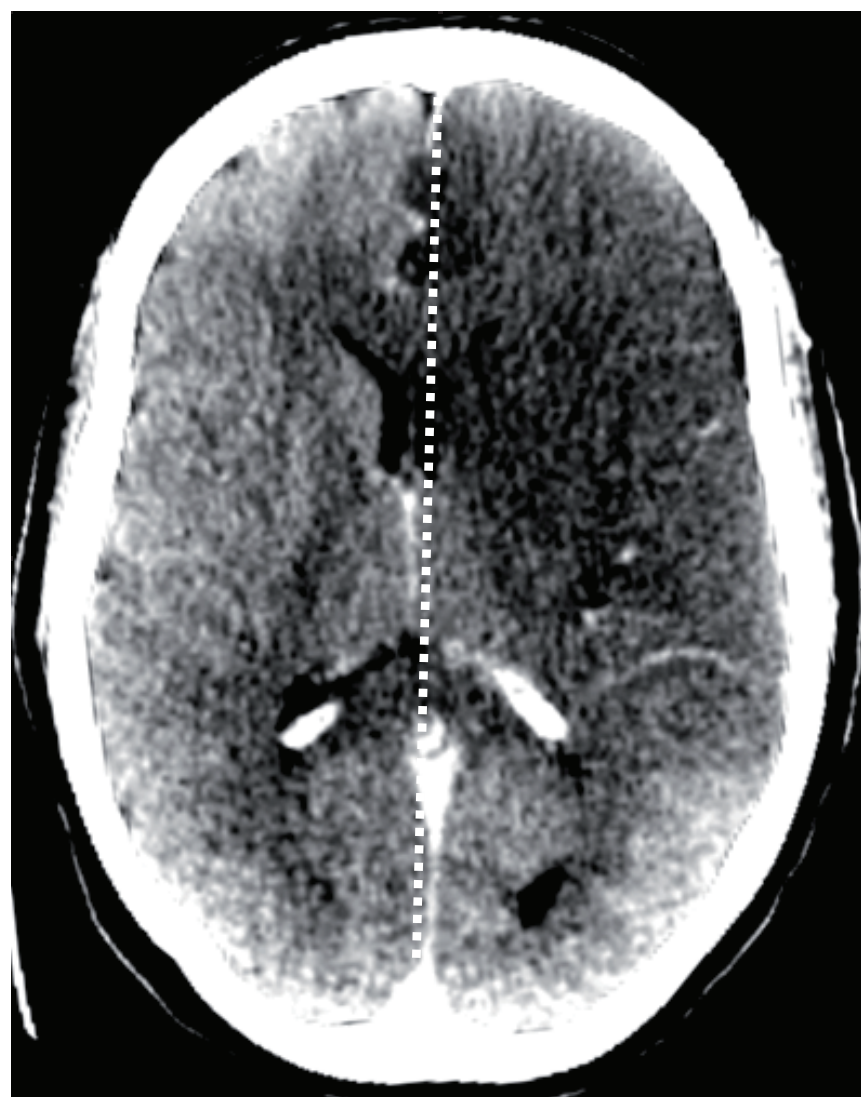

Figure 2a: 15 hours after presentation - left sided ACA and MCA territory infarction with early signs of mass effect (dotted line $=$ midline $)$

\section{ISCHAEMIC STROKE}

Ischaemic stroke account for $80 \%$ of all strokes, and is the leading cause of acquired disability in the United Kingdom. It results from a sudden cessation of adequate amounts of blood reaching areas of the brain, causing rapid onset neurological deficit. Early intervention (i.e. with thrombolytic therapy) significantly improves clinical outcomes. The role of unenhanced CT in stroke presentations is to rule out haemorrhage (contraindication of thrombolysis) and help detect these hyper-acute signs of stroke.

\section{DIFFERENTIAL DIAGNOSIS FOR DENSE MCA}

- Calcified atherosclerotic disease

- Raised haematocrit

- HSV encephalitis (rare)

\section{REFERENCES}

Ashok Srinivasan, et al. (2006) State-of-the-art imaging of acute stroke, RadioGraphics, 26, pp. S75-S95 [online]. Available at: http://pubs.rsna.org/doi/full/10.1148/ rg.26si065501 (accessed 26.6.17)

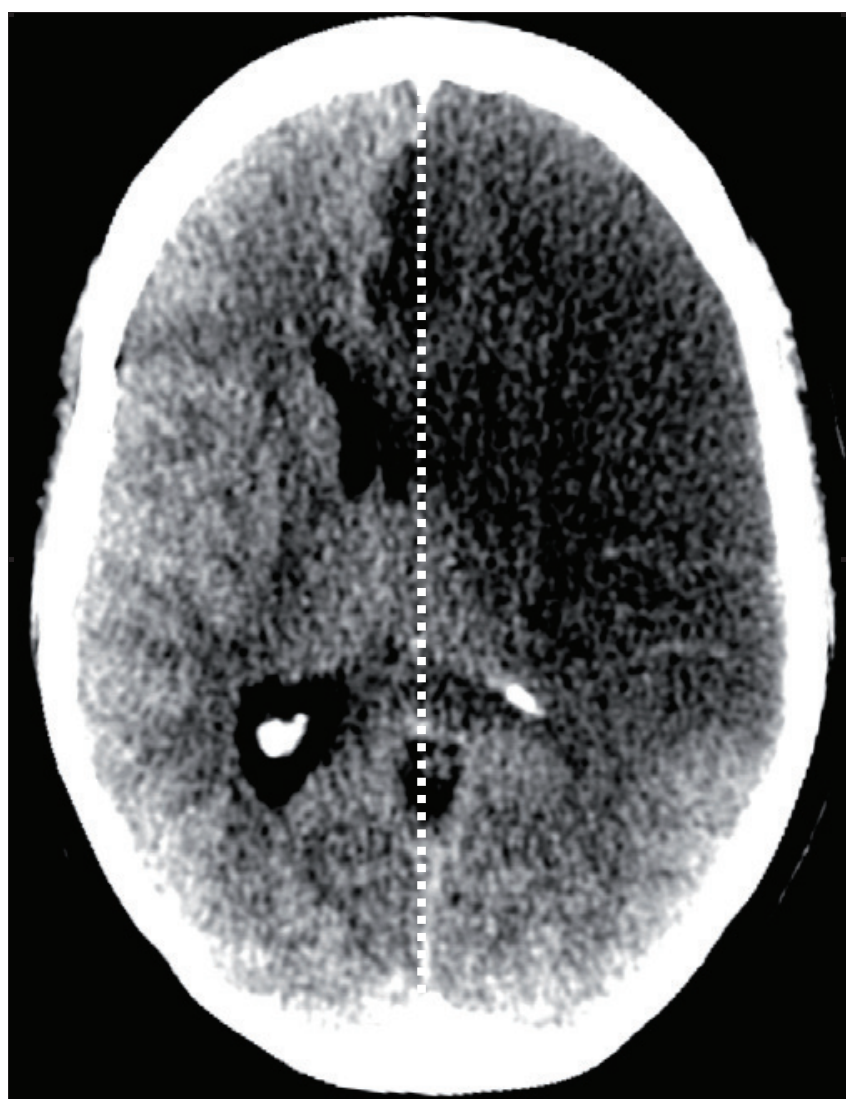

Figure 2b: 24 hours - shows left sided ACA and MCA territory infarction with worsening mass effect (dotted line $=$ midline $)$

Radiopedia.org (2017) Hyperdense MCA sign (brain) [online]. Available at: https://radiopaedia.org/articles/ hyperdense-mca-sign-brain (accessed 26.6.17)

Radiopedia.org (2017) Ischaemic stroke [online]. Available at: https://radiopaedia.org/articles/ischaemic-stroke (accessed 26.6.17)

\section{Correspondence to:}

Sophie Connor, ST1 Radiology Registrar at RLI connor.sophie@mbht.nhs.uk 